\title{
Transformar a Gestão do Sistema de Saúde é o Desafio do Futuro
}

\section{João Abreu de Faria Bilhim Editor}

Salvaguardadas as diferenças entre Portugal e Brasil - 10 milhões para cerca de 22 milhões de habitantes e de geografia humana, económica, física, política e cultural - ambos os países dão sinais de querer transformar a gestão de seus sistemas de saúde.

O Serviço Nacional de Saúde (SNS) em Portugal acaba de fazer 40 anos e sendo um pouco mais velho do que o Serviço Único de Saúde (SUS) Brasileiro, revela já sinais de esgotamento e de transformação, pois na última década Portugal e Brasil se modificaram muito em termos demográficos, em termos epidemiológicos, em termos económicos, em termos sociais. Assim, as expectativas das pessoas são hoje muito diferentes e os cidadãos são felizmente mais exigentes.

Em Portugal, no dia 18 de julho, na sessão «Desafios do SNS e a sua história», promovido no âmbito das comemorações dos 40 anos do SNS, foi apresentado o livro «Serviço Nacional de Saúde - Breve interpretação e bases para a sua transformação» que contém sugestões concretas para a reforma do SNS e inspiração, em nosso entender, para o SUS do Brasil.

Com dezenas de contribuições, o livro é a primeira iniciativa da Fundação para a Saúde - Serviço Nacional de Saúde (FSNS) para assinalar os 40 anos do SNS e contém depoimentos inéditos e faz propostas para um SNS melhor, que responda aos desafios atuais e de futuro. O Governo Português reconheceu nessa sessão que «seria péssimo para os portugueses deixar cair a ideia generosa do SNS, que é um instrumento de coesão social, de melhoria das condições de vida, de esperança e de construção da felicidade".

Tanto em Portugal quanto no Brasil muitos reconhecem que é preciso discutir a saúde não como política do Ministério da Saúde, mas como um dever permanente do Estado e direito do cidadão. Aliás, em editorial anterior, já defendemos que o direito à saúde se poderá tratar de um direito fundamental como o direito à liberdade.

Por isso, no Brasil é preciso retomar os princípios básicos da reforma sanitária, previstos na Constituição Federal, que não se limitaram à criação do Sistema Único de Saúde (SUS). A necessidade de identificar conquistas e desafios do sistema de saúde brasileiro e português é uma tarefa contínua e, apesar das diferenças que nos separam, há muito que nos une nomeadamente o reconhecimento de que o atual modelo - SNS e SUS - desresponsabiliza os dirigentes e tem de ter mais financiamento. O subfinanciamento é o grande obstáculo para a ampliação do acesso e melhoria na qualidade dos serviços.

O atual número da Revista Eletrônica Gestão \& Saúde $(\mathrm{G} \& S)$ representa um contributo para esta discussão crucial do SUS. Com efeito, traz nove artigos cinco dos quais dedicados às políticas e governança de saúde: Políticas de saúde, organização e mobilidade social em uma região rural brasileira: perspectivas dos informantes chave; Gestão e governança em saúde: um ensaio sobre conceitos aplicados aos estudos nacionais; Gestão de Saúde Pública através de Organizações 
Sociais (OS): breve revisão de literatura; Auditoria de Riscos em Saúde: Comparação entre Cenários Internacional e Nacional; Necessidades de saúde no período perioperatório: subsídios para uma assistência centrada no paciente.

Quatro são dedicados à enfermagem: Community health and public health nursing: a systematic literature review; Absenteísmo entre técnicos de enfermagem de uma unidade de pronto atendimento; A Gestão na Graduação em Saúde Coletiva e Enfermagem: uma análise dos Projetos Político-Pedagógicos; Observação participante nas pesquisas de gestão em enfermagem: revisão integrativa.

Há um equilíbrio entre a dimensão académica e a profissional neste número da Revista Eletrônica Gestão \& Saúde (G\&S). O leitor encontrará três trabalhos dedicados à revisão da literatura e, em geral, os trabalhos publicados relevam significativamente a importância dada à pesquisa qualitativa balanceada com a quantitativa na esteira da tradição desta publicação.

Os problemas versados são diversos, mas complementares. Assim, o leitor, de acordo com seus interesses, se deparará com os seguintes temas: importância do serviço de saúde centrado no paciente; papel da auditoria de risco na qualidade de serviço; papel das organizações sociais na gestão de saúde pública; o contributo da técnica de recolha de dados oriunda da antropologia conhecida por "observação participante" para a gestão em enfermagem; conceitos sobre governança e gestão em saúde; estudo sobre mobilidade social em uma região rural do Brasil; reflexão sobre curso de graduação em saúde coletiva; absenteísmo e cotidiano de vida e de trabalho entre os enfermeiros; as competências e intervenções dos enfermeiros de saúde pública numa perspetiva internacional.

Para melhor compreender o papel dos profissionais de saúde e dos seus dirigentes lança-se mão da teoria da estruturação de Anthony Gidens. Com efeito, para o autor, a forma como os agentes, profissionais de saúde, experimentam o mundo, influenciará a forma como veem e compreendem o sistema de saúde e, portanto, como agem. A teoria da estruturação incorpora uma gama de ideias sociológicas para explorar a prática social e as interações.

Para a teoria da estruturação as pessoas carregam e criam todo o tipo de scripts e esquemas para lidar com situações, produzindo e reproduzindo práticas sociais que geralmente sobrevivem como padrões recursivos e práticas de rotina. Não há transformação do sistema de saúde sem os profissionais e sem que os seus dirigentes assumam um papel mais ativo e reflexivo.

Espera-se que os leitores possam exercitar a sua reflexividade com este número da Revista Eletrônica Gestão \& Saúde (G\&S), assumindo, quer académica quer profissionalmente, um papel mais ativo na gestão do sistema de saúde. A reflexividade ajuda a tornar a prática social mais clara, trazendo o conhecimento de um nível prático tácito, para um nível que pode ser analisado de forma discursiva. Por isso, com esta publicação toda a equipe da Revista Eletrônica Gestão \& Saúde (G\&S) está segura de que estará a contribuir para a transformação da gestão do sistema de saúde que tudo indica ser o desafio do futuro. 